\title{
IONOSPHERIC HOT SPOT AT HIGH LATITUDES
}

\author{
R.W. Schunk and J.J. Sojka \\ Center for Atmospheric and Space Sciences \\ Utah State University \\ Logan, Utah 84322
}

Abstract. A hot spot (or spots) can occur in the high-latitude ionsophere depending on the plasma convection pattern. The hot spot corresponds to a small magnetic local time-magnetic latitude region of elevated ion temperatures located near the dusk and/or dawn meridians. For asymmetric convection electric field patterns, with enhanced flow in either the dusk or dawn sector of the polar cap, a single hot spot should occur in association with the strong convection cell. However, on geomagnetically disturbed days, two strong convection cells can occur, and hence, two hot spots should exist. The hot spot should be detectable when the electric field in the strong convection cell exceeds about $40 \mathrm{mV} \mathrm{m}{ }^{-1}$. For electric fields of the order of $100 \mathrm{mV} \mathrm{m}^{-1}$ in the convection cell, the ion temperature in the hot spot is greatest at low altitudes, reaching $4000{ }^{\circ} \mathrm{K}$ at $160 \mathrm{~km}$, and decreases with altitude in the F-region. An ionospheric hot spot (or spots) can be expected at all seasons and for a wide range of solar cycle conditions.

\section{Introduction}

During the past few years, we have developed a comprehensive model of the convecting high-latitude ionosphere in order to determine the extent to which various chemical and transport processes affect the ion composition and electron density at F-region altitudes (cf. Schunk and Raitt, 1980; Sojka et al, 1981a,b). Our numerical model produces time-dependent, threedimensional ion density distributions for the ions $\mathrm{NO}^{+}, \mathrm{O}_{2}{ }^{+}$, $\mathrm{N}_{2}{ }^{+}, \mathrm{O}^{+}, \mathrm{N}^{+}$and $\mathrm{He}^{+}$. The model takes account of diffusion, thermospheric winds, electrodynamic drifts, polar wind escape, energy dependent chemical reactions, magnetic storm induced neutral composition changes, and ion production due to solar EUV radiation and energetic particle precipitation.

Recently, we have improved our high-latitude ionospheric model by including thermal conduction and diffusion-thermal heat flow terms in the ion energy equation so that we could rigorously model ion temperature variations throughout the F-region. In an initial investigation (Schunk and Sojka, 1982), we studied the ion temperature variations in the daytime highlatitude F-region for a range of geophysical conditions, including solar cycle, seasonal, and geomagnetic activity variations. However, the calculations were performed for a location poleward of the auroral oval and only for steady state conditions at local noon.

In this study, we obtained a time-dependent threedimensional ion temperature distribution for the high-latitude ionosphere for an asymmetric convection electric field pattern with enhanced flow in the dusk sector of the polar region. As will be shown, such a convection pattern produces a hot spot in the ion temperature distribution which coincides with the location of the strong convection cell. Since asymmetric electric field patterns are commonly found in satellite observations (Heppner, 1977) and in incoherent backscatter radar observations (J.C. Foster, private communication, 1981), the hot spot should be a fairly common feature of the high-latitude ionosphere.

Copyright 1982 by the American Geophysical Union.

Paper number 2L1185.

$0094-8276 / 82 / 002 \mathrm{~L}-1185 \$ 3.00$

\section{Ionospheric Hot Spot}

The complete description of our high-latitude ionospheric model is given elsewhere (Schunk and Raitt, 1980; Sojka et al, 1981a,b; Schunk and Sojka, 1982) and will not be repeated here. Briefly, we follow a field tube of plasma as it convects through a moving neutral atmosphere. Altitude profiles of the ion temperature and densities are obtained by solving the appropriate continuity, momentum and energy equations including numerous high-latitude processes. By following many field tubes of plasma we can construct a time-dependent threedimensional model of the high-latitude ionosphere.

In this study, an asymmetric electric field pattern was adopted with enhanced plasma flow in the dusk sector of the polar region. Such an asymmetry in the convection electric field is commonly found in both satellite (Heppner, 1977) and incoherent backscatter (J.C. Foster, private communication, 1981) electric field observations. For the calculations, a total cross-tail magnetospheric potential of $90 \mathrm{kV}$ was selected, which produces horizontal convection velocities of up to $2 \mathrm{~km} / \mathrm{s}$ at ionsopheric altitudes in the strong convection cell. Further details about the characteristics of the adopted convection pattern are given by Sojka et al (1981b).

The calculations were performed for winter solstice and solar maximum conditions. However, as shown by Schunk and Sojka (1982), the ion heating associated with electric fields greater than about $40 \mathrm{mVm}^{-1}$ produces a larger change in the ion temperature than that associated with solar cycle and seasonal variations. Therefore, the ionospheric hot spot that we describe below for winter solstice and solar maximum conditions should be qualitatively similar to those obtained for other geophysical conditions.

Figure 1 shows contours of the ion temperature in the magnetic quasi-inertial frame at 0 UT for altitudes of 360 and $800 \mathrm{~km}$. At other universal times the results are similar, and consequently, they will not be presented. The intense heating in the strong convection cell in the dusk sector of the polar ionosphere is clearly seen at $360 \mathrm{~km}$, where $\mathrm{T}_{\mathrm{i}}$ reaches $3500^{\circ} \mathrm{K}$ near the center of the cell. At the center of the cell and at lower altitudes $(-160 \mathrm{~km})$ the ion temperature reaches $4400^{\circ} \mathrm{K}$. This heating, which is a consequence of ion-neutral frictional interactions, is less evident at high altitudes $(800 \mathrm{~km})$, with the result that $\mathrm{T}_{\mathrm{i}}$ decreases with altitude in the F-region in the strong convection cell. Also, at high altitudes, thermal conduction and horizontal transport effects become important, and the hot spot becomes less evident. A feature acting to mask the hot spot at high altitudes is the ring of enhanced ion temperatures that is associated with the auroral oval.

Figures 2 and 3 show the three-dimensional structure of the hot spot, where selected contours of the ion temperature are shown as a function of magnetic latitude, magnetic local time (MLT), and altitude. In Figure 2 the $2000^{\circ} \mathrm{K}$ ion temperature is contoured, while in Figure 3 the $3500^{\circ} \mathrm{K}$ contour is shown. It is apparent that the highest ion temperatures are confined to a small MLT-magnetic latitude region near the center of the convection cell and occur at low altitudes where the ion-neutral frictional heating is the greatest (Figure 3). However, the $2000^{\circ} \mathrm{K}$ contour in the hot spot encompasses a much larger MLTmagnetic latitude region and extends to high altitudes, where it also encompasses the enhanced ion temperatures associated with the auroral oval (Figure 2). 


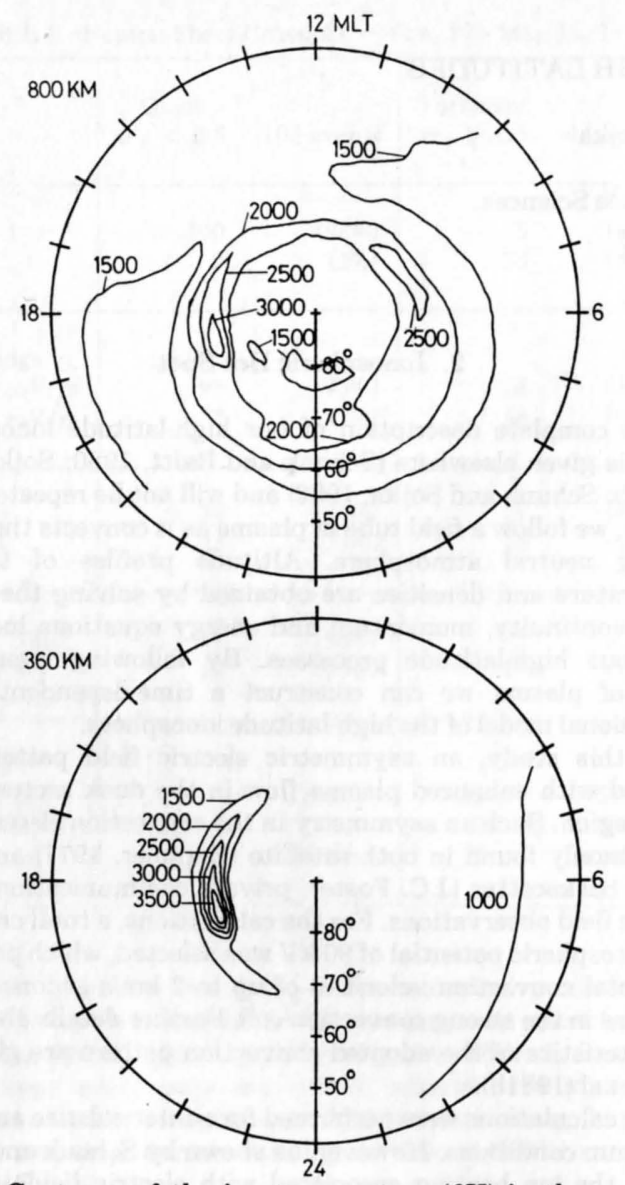

Fig. 1. Contours of the ion temperature $\left({ }^{\circ} \mathrm{K}\right)$ in the magnetic quasi-inertial frame for altitudes of $360 \mathrm{~km}$ (bottom panel) and $800 \mathrm{~km}$ (top panel). Magnetic local time (MLT) is indicated by tick marks at hourly intervals and magnetic latitude is indicated on the vertical scale.

Figure 4 shows ion temperature profiles as a function of altitude at selected locations both inside and outside of the hot spot. Outside of the hot spot the ion temperature profiles display the characteristic behavior found at mid-latitudes. That is, at low altitudes the ion temperature is strongly coupled to the neutral temperature, while at higher altitudes the ion temperature first increases with altitude owing to ion-electron

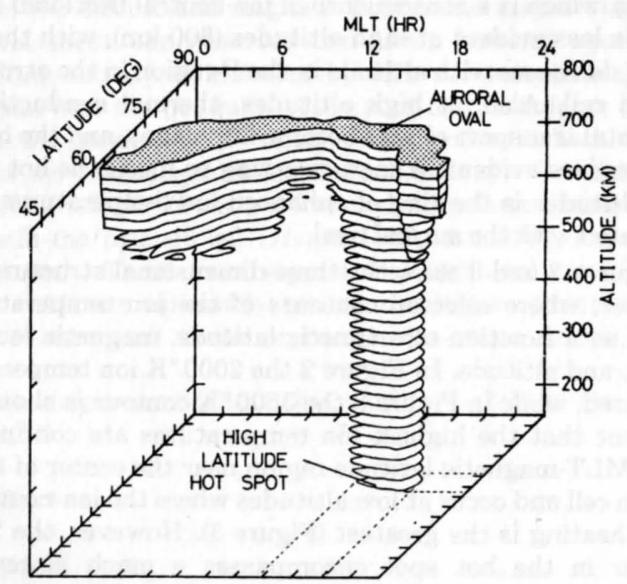

Fig. 2. The $2000^{\circ} \mathrm{K}$ ion temperature contour versus magnetic latitude and MLT at selected altitudes. The contours are shown every $20 \mathrm{~km}$ from 160 to $800 \mathrm{~km}$.

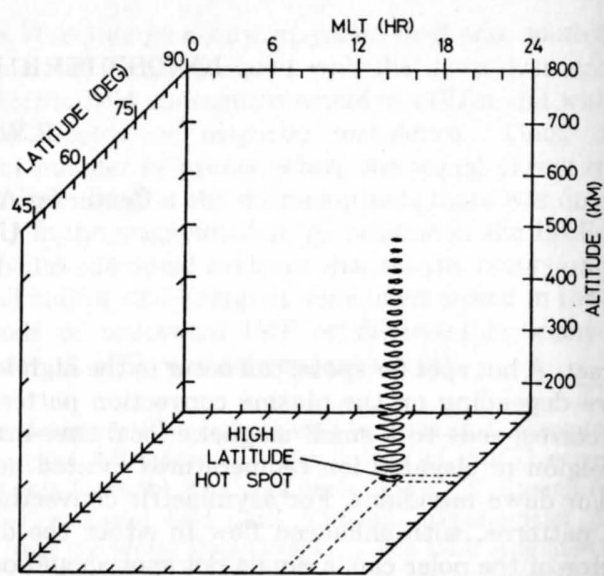

Fig. 3. The $3500^{\circ} \mathrm{K}$ ion temperature contour versus magnetic latitude and MLT at the same altitudes used for Figure 2.

thermal coupling and then becomes constant with altitude owing to the dominance of thermal conduction. In the hot spot, on the other hand, a markedly different behavior is obtained in that the ion temperature either decreases with altitude or is approximately constant with altitude in the F-region, depending on the strength of the convection electric field and the location in the hot spot. At the locations where the ion temperature decreases with altitude, the ion heat flow is upward from the lower ionosphere to high altitudes, which is opposite to that normally found at middle and high latitudes.

\section{Summary and Discussion}

A time-dependent, three-dimensional model of the convecting high-latitude ionosphere was used to calculate the ion temperature distribution for an asymmetric electric field pattern with enhanced plasma flow in the dusk sector of the polar ionosphere. Associated with this asymmetric electric field pattern is an ionospheric hot spot, which corresponds to a region of elevated ion temperatures whose location coincides with that of the strong convection cell. In the hot spot the ion temperature either decreases with altitude or is approximately constant with altitude in the F-region. At the locations where the ion

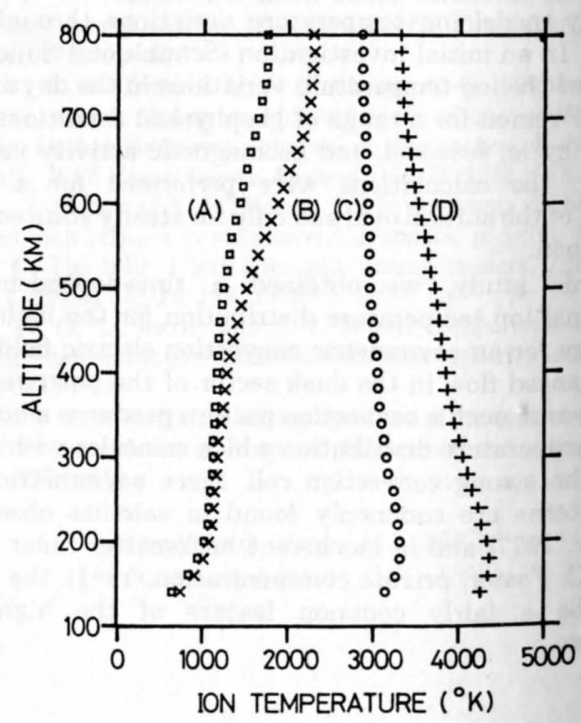

Fig. 4. Ion temperatures as a function of altitude at selected locations. The locations are: (A) dayside, equatorward of auroral oval; (B) dayside, auroral oval; (C) edge of hot spot; and (D) center of hot spot. 
temperature decreases with altitude, the ion heat flow is upward from the lower ionosphere to high altitudes.

Measurements indicate that asymmetric electric field patterns are a common feature of the high-latitude ionosphere and that if the strong convection cell appears in the dusk sector of the northern hemisphere it will simultaneously occur in the dawn sector of the southern hemisphere (Heppner, 1977). Since the ionospheric hot spot is associated with the strong convection cell, it should also be prevalent and display an asymmetry with regard to the northern and southern hemispheres. Furthermore, for very active geomagnetic conditions two strong convection cells can occur simultaneously, one in the dusk sector and the other in the dawn sector (Heppner, 1977). For these less frequent conditions, there should be a hot spot associated with each convection cell. The characteristics of each hot spot should be similar to that described above for the case when only one strong convection cell exists. An ionospheric hot spot (or spots) can be expected at all seasons and for a wide range of solar cycle conditions.

Unfortunately, at the present time there is very little experimental information on ion temperatures in the high latitude F-region (cf. Schunk and Sojka, 1982). Although the extensive AE-C database has been used for a morphological study of Te at $300 \mathrm{~km}$ (Brinton et al, 1978), a similar study for $\mathrm{T}_{\mathrm{i}}$ has not yet been done. Satellite measurements of elevated ion temperatures have been reported at high latitudes in the general area where the hot spots should be located (Knudsen and Sharp, 1967). The satellite measurements showed a UT variation of the elevated ion temperatures, indicating that the phenomenon was associated with the magnetic frame. However, due to a satellite timing problem, the actual location of the elevated ion temperatures cannot be established. Also, to date very little information has been published on ion temperatures obtained from high-latitude incoherent scatter radars. This is probably due to the fact that an unambiguous determination of $T_{i}$ can be obtained only if the ion composition is known. However, the ion composition at high-latitudes is highly variable (Brinton et al, 1978).

Recently, the Millstone Hill incoherent scatter radar has measured both ion temperatures and line-of-sight plasma convection velocities in the high latitude F-region (J.V. Evans, private communication, 1982), and these data show clear evidence for the existence of ionospheric hot spots. Of the limited data available at this time, there are several days where either one or two hot spots exist, with the centers of the hot spots being near the dawn and dusk meridians.

Before presenting the experimental evidence for hot spots, we note that a radar cannot take a snapshot of the ionosphere, but instead obtains the ionsopheric parameters as it rotates around with the earth. Therefore, if a region of enhanced ion temperatures is observed in a given local time sector, such as dawn or dusk, one might argue that it is not a hot spot but simply reflects a fortuitous variation of the cross-tail magnetospheric potential with time. That is, the cross-tail potential just happened to be large when the radar was near the dusk (or dawn) meridian, while at other times it was small. In an effort to avoid this problem, we selected a day when the Kp index remained high throughout the measurement time, so it is likely that the large-scale convection pattern did not change markedly during this time. Therefore, any hot spots observed should be associated with the plasma convection pattern, and should not reflect a fortuitous temporal variation of the magnetospheric cross-tail potential. In addition, we also selected data at an altitude of $500 \mathrm{~km}$, where it is safe to assume that the ion composition is dominated by $\mathrm{O}^{+}$.

Figure 5 shows contours of the ion temperature (panel A) and the line-of-sight plasma drift velocity at $500 \mathrm{~km}$ as observed from Millstone Hill over a 24 hour period on October 10-11, 1980. The line market UT corresponds to the local time when the observation began. No data were collected at dip latitudes greater than about $75^{\circ}$ (shown by the dashed circles). For this
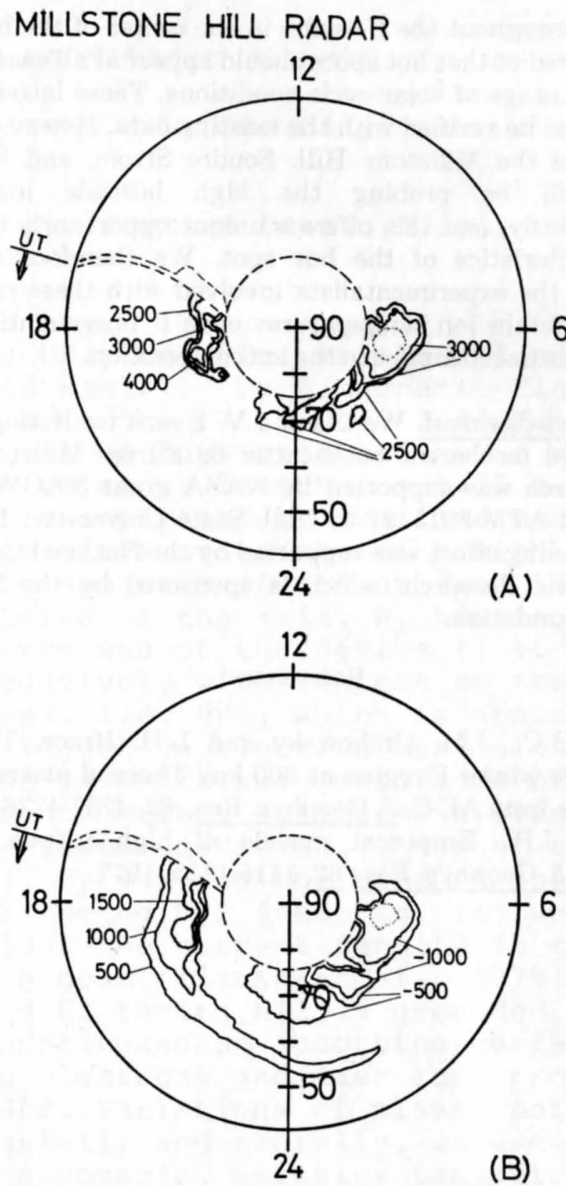

Fig. 5. Contours of ion temperature (panel A) and line-of-sight ion drift velocity (panel B) observed at an altitude of $500 \mathrm{~km}$ from Millstone Hill over a 24 hour period on October 10-11, 1980. The temperatures are in ${ }^{\circ} \mathrm{K}$ and the velocities are in $\mathrm{m} / \mathrm{s}$, with \pm being toward and away from the radar. The panels are polar diagrams with local time indicated on the outer circle and dip latitude on the vertical scale.

day, $\mathrm{Kp}$ remained above 5 from the time measurement began until about 10 LT. Consequently, it is likely that the basic convection pattern persisted during this time period. Panel B clearly displays two distinct regions where the north-south, lineof-sight plasma convection velocity exceeds $1 \mathrm{~km}$. When the full vector is constructed with the aid of our convection model, these line-of-sight velocities are consistent with two strong convection cells, one at $1800 \mathrm{LT}$ and the other at $0600 \mathrm{LT}$. In both cells, horizontal drift speeds in excess of $2 \mathrm{~km} / \mathrm{s}$ are obtained.

Associated with the large convection velocities are very high ion temperatures, with $\mathrm{T}_{\mathrm{i}}$ reaching $4000^{\circ} \mathrm{K}$ in a small region near the dusk meridian. The enhanced ion temperatures are confined to the general region where the large line-of-sight convection velocities exist, forming two distinct hot spots in the highlatitude ionosphere. However, the highest ion temperatures do not coincide with the largest line-of-sight velocities because these velocities correspond to only one component of the full vector. Outside of the two hot spots, the ion temperatures are very uniform, with $\mathrm{T}_{\mathrm{i}}<2000^{\circ} \mathrm{K}$.

The observations shown in Figure 5 support our theoretical predictions about the presence of an ionospheric hot spot (or spots). It is located in a small local time-magnetic latitude region near dawn and/or dusk, and the elevated ion temperatures are strongly correlated with large plasma convection speeds. However, we predict that the highest ion temperatures occur at low altitudes and that $\mathrm{T}_{\mathrm{i}}$ decreases with 
altitude throughout the F-region in the center of the hot spot. Also, we predict that hot spots should appear at all seasons and for a wide range of solar cycle conditions. These latter predictions cannot be verified with the existing data. However, in the near future the Millstone Hill, Sondre Strom, and EISCAT radars will be probing the high latitude ionosphere simultaneously, and this offers a unique opportunity to study the characteristics of the hot spot. We therefore strongly encourage the experimentalists involved with these radars to routinely obtain ion temperatures even if uncertainties exist owing to the uncertainties in the ion composition.

Acknowledgement. We thank J.V. Evans for letting us use unpublished incoherent backscatter data from Millstone Hill. This research was supported by NASA grant NAGW-77 and NSF grant ATM-8015497 to Utah State University. The computer modeling effort was supported by the National Center for Atmospheric Research, which is sponsored by the National Science Foundation.

\section{References}

Brinton, H.C., J.M. Grebowsky and L.H. Brace, The high latitude winter F-region at $300 \mathrm{~km}$ : Thermal plasma observations from AE-C, J. Geophys. Res., 83, 4767-4776, 1978.

Heppner, J.P., Empirical models of high-latitude electric fields, J. Geophys. Res., 82, 1115-1125, 1977.
Knudsen, W.C., and G.W. Sharp, Ion temperatures measured around a dawn-dusk-auroral-zone satellite orbit, J. Geophys. Res., 72, 1061-1072, 1967.

Schunk, R.W. and W.J. Raitt, Atomic nitrogen and oxygen ions in the daytime high-latitude F-region, J. Geophys. Res., $85,1255-1272,1980$.

Schunk, R.W. and J.J. Sojka, Ion temperature variations in the daytime high-latitude F-region, J. Geophys. Res., 87, 5169-5183, 1982.

Sojka, J.J., W.J. Raitt and R.W. Schunk, A theoretical study of the high-latitude winter F-region at solar minimum for low magnetic activity, J. Geophys. Res., 86, 609-621, 1981a.

Sojka, J.J., W.J. Raitt and R.W. Schunk, Plasma density features associated with strong convection in the winter high-latitude F-region, J. Geophys. Res., 86, 6908-6916, 1981b.
(Received April 5, 1982; revised May 5, 1982; accepted August 4, 1982.) 